\title{
Angiopoietin-2 is increased in sepsis and inversely associated with nitric oxide-dependent microvascular reactivity
}

\author{
Joshua S Davis ${ }^{1,2}$, Tsin W Yeo $^{1}$, Kim A Piera ${ }^{1}$, Tonia Woodberry ${ }^{1}$, David S Celermajer ${ }^{3}$, Dianne P Stephens ${ }^{4}$, \\ Nicholas M Anstey ${ }^{1,2^{*}}$
}

\begin{abstract}
Introduction: Angiopoietin-2 (ang-2), an angiogenic peptide released by endothelial cell Weibel-Palade bodies (WPBs), increases endothelial activation and vascular permeability. Ang-2 is raised in severe sepsis but the mechanisms underlying this are not known. Nitric oxide (NO) inhibits WPB exocytosis, and bioavailability of endothelial NO is decreased in sepsis. We hypothesized that endothelial NO bioavailability would be inversely correlated with ang-2 concentrations in sepsis.
\end{abstract}

Methods: Plasma ang-2, vascular endothelial growth factor (VEGF) and endothelial-active cytokines were assessed in 83 patients with early sepsis and 41 hospital controls, and related to reactive hyperaemia-peripheral arterial tonometry, RH-PAT, a measure of endothelial NO bioavailability.

Results: Plasma Ang-2 was elevated in sepsis (median [interquartile range (IQR)], ng/ml: severe sepsis 12.4 [8.5-33.4], sepsis without organ failure 6.1 [5.0-10.4], controls 2.7 [2.2-3.6], $P<0.0001)$. It correlated inversely with RH-PAT $(r=-0.38, P<0.0001)$ and positively with IL-6 $(r=0.57, P<0.0001)$ and degree of organ failure (sequential organ function assessment score) $(r=0.58, P<0.0001)$. The correlation of ang-2 with RH-PAT persisted after controlling for sepsis severity. In a longitudinal mixed-effects model, recovery of RH-PAT over time was associated with decline in ang-2.

Conclusions: Ang-2 is elevated in proportion to sepsis severity, and inversely correlated with NO-dependent microvascular reactivity. Impaired endothelial NO bioavailability may contribute to increased endothelial cell release of ang-2, endothelial activation and capillary leak. Agents that increase endothelial NO bioavailability or inhibit WPB exocytosis and/or Ang-2 activity may have therapeutic potential in sepsis.

\section{Introduction}

Microvascular and endothelial dysfunction are central to the pathophysiology of sepsis, contributing to organ dysfunction even in the setting of normal post-resuscitation haemodynamics [1]. Angiopoietin-2 (ang-2), an angiogenic peptide, activates endothelial cells and increases vascular inflammation. It functions as an autocrine mediator of the endothelium and is stored predominantly in endothelial cells [2]. Ang-2 is a ligand of the tyrosine kinase receptor, Tie-2, and antagonises the angiopoietin

\footnotetext{
* Correspondence: Nicholas.Anstey@menzies.edu.au

${ }^{1}$ International Health Division, Menzies School of Health Research and
Charles Darwin University, Ellengowan Drive, Casuarina, Darwin, NT 0810,

${ }^{1}$ International Health Division, Menzies School of Health Research and
Charles Darwin University, Ellengowan Drive, Casuarina, Darwin, NT 0810, Australia
}

(c) 2010 Davis et al.; licensee BioMed Central Ltd. This is an open access article distributed under the terms of the Creative Commons Attribution License (http://creativecommons.org/licenses/by/2.0), which permits unrestricted use, distribution, and reproduction in any medium, provided the original work is properly cited.

1-induced Tie-2 receptor autophosphorylation responsible for the maintenance of endothelial cell quiescence [3]. This results in endothelial cells being sensitized to the effects of pro-inflammatory cytokines and vascular endothelial growth factor (VEGF), resulting in a loss of endothelial cell quiescence and an increase in vascular activation and inflammation.

Levels of circulating ang- 2 have been shown to be raised in human sepsis [4-6] and, more recently, to correlate with mortality [7-9] and pulmonary vascular leak $[10,11]$. Despite a growing interest in ang-2 in sepsis, the mechanisms underlying elevated ang- 2 levels in patients with sepsis are unclear. Ang-2 is co-packaged with von Willebrand Factor (vWF) within endothelial 
cell Weibel-Palade bodies (WPBs) and is immediately released upon endothelial cell stimulation and WPB exocytosis [12]. In-vitro studies demonstrate that exocytosis of WPBs can be triggered by multiple secretagogues, including thrombin, histamine, epinephrine, VEGF, and hypoxia [13]. However, there are only two known inhibitors of WPB release: nitric oxide (NO) and hydrogen peroxide $\left(\mathrm{H}_{2} \mathrm{O}_{2}\right)$, of which $\mathrm{NO}$ is thought to be the most important [14].

We have recently demonstrated impaired microvascular reactivity in patients with sepsis by reactive hyperaemia peripheral arterial tonometry (RH-PAT) [15], which is at least $50 \%$ NO-dependent and thus provides an estimate of endothelial NO bioavailability [16]. In contrast to earlier hypotheses suggesting major overproduction of NO in patients with sepsis [17], there is now increasing evidence that systemic NO production is normal or decreased in humans with sepsis $[18,19]$. Impaired endothelial NO bioavailability may underlie increased WPB exocytosis in sepsis, and thus the release of ang-2 from endothelial cells. However, the relation between endothelial NO bioavailability and measures of WPB release in sepsis has not been determined. We hypothesized that plasma ang-2 levels in patients with sepsis would be raised in proportion to disease severity and would be inversely related to endothelial NO bioavailability, as estimated by RH-PAT.

\section{Materials and methods}

\section{Study design and setting}

We performed a prospective observational study at a 350-bed teaching hospital in tropical Australia, with an 18-bed mixed ICU. Prior approval was obtained from the Human Research Ethics Committee of the Menzies School of Health Research and the Department of Health and Community Services. Written informed consent was obtained from all participants or their next of kin where necessary.

\section{Participants}

The study subjects were adults ( $\geq 18$ years) hospitalized with sepsis, who were enrolled in a previously reported study of microvascular reactivity; more detail of subject recruitment, patient characteristics and study procedures are provided in this paper [15]. Some of the data included in the current paper have been previously reported (RH-PAT index, intra-cellular adhesion molecule-1 [ICAM1], E-selectin and IL-6), but are included here for comparison with Ang-2. Sepsis was defined as a proven or suspected infection plus at least two criteria for the systemic inflammatory response syndrome (SIRS) present within the past four hours [20]. Septic patients were eligible for enrolment within 24 hours of their admission to the ICU, or within 36 hours of admission to the ward. Exclusion criteria were: coagulopathy (platelets $\leq 20 \times 10^{9} / \mathrm{L}$, activated partial thromboplastin time $\geq 70$ seconds, international normalized ratio $\geq 2.0$ ); smoking of tobacco within the preceding four hours; and receipt of intravenous nitrates. Control subjects were adults recruited from hospital patients with no clinical or laboratory evidence of inflammation or infection, and who had not met SIRS criteria within the past 30 days. Septic patients were prospectively classified as severe sepsis, or sepsis without organ failure. Severe sepsis was defined as sepsis with organ dysfunction or shock at the time of enrolment according to American College of Chest Physicians/Society of Critical Care Medicine consensus criteria $[15,20]$.

\section{Laboratory assays}

Venous blood was collected in lithium heparin tubes at baseline and two to four days later, and plasma was frozen at $-80^{\circ} \mathrm{C}$. Control patients had blood collected at baseline only. Plasma concentrations of VEGF, ICAM-1 and E-selectin were measured by ELISA (R\&D Systems, Minneapolis, MN, USA), according to the manufacturer's instructions. The ELISA used to determine plasma Ang-2 concentrations (R\&D Systems, Minneapolis, MN, USA) reports a lower limit of detection of $8.3 \mathrm{pg} / \mathrm{ml}(0.0083 \mathrm{ng} / \mathrm{ml})$, with coefficients of variation for intra-assay and inter-assay precision of $4.2 \%$ and $7.4 \%$, respectively.

IL- 6 and TNF $\alpha$ were measured by flow cytometry using a cytokine bead array (CBA; BD Biosciences, Franklin Lakes, NJ, USA).

\section{Measurement of microvascular reactivity/endothelial NO bioavailability}

Microvascular reactivity was measured at the bedside by RH-PAT (Itamar Medical, Caesarea, Israel), a non-invasive method of assessing endothelial function [21], which is at least $50 \%$ dependent on endothelial NO production [16]. We have previously reported internal validation and repeatability of RH-PAT in acute inflammatory states [22]. PAT was measured in a fingertip before and after a five-minute ischemic stress at the forearm, generating an RH-PAT index, normalized to the control arm, as previously described [15]. All studies were performed after resuscitation and at least an hour of hemodynamic stability in a quiet room at $25^{\circ} \mathrm{C}$, with the patient in a recumbent position.

\section{Statistical methods}

All analyses were hypothesis based and were specified a priori. Continuous variables were compared using Student's t-test/analysis of variance or Mann Whitney $\mathrm{U}$ test/Kruskal-Wallis test for parametric and nonparametric variables, respectively. Categorical variables 
were compared using Fisher's exact test. For the ELISA and CBA assays, values below the lower limit of detection were assigned a value of halfway between zero and the lower limit of detection for the purposes of analysis. Correlates with baseline Ang-2 were determined using Spearman's coefficient. For multivariate analysis, linear regression with backward selection was used. All independent variables with a Wald $P$-value of less than 0.10 on univariate analysis, or which were considered biologically important were included in the initial model. Variables with a Wald $P$-value of 0.05 or more were sequentially dropped from the model. The natural logarithm of Ang-2 was used as the dependent variable, because Ang-2 was right-skewed and log transformation lead to a normal distribution. To control for covariates in the relationship between Ang-2 and RH-PAT index, the covariate in question was added to a linear regression model with log Ang2 as the independent variable and RH-PAT index as the dependent variable. To examine longitudinal correlations, linear mixed-effects models were used. A two-sided $P$ value of less than 0.05 was considered significant. All analyses were performed using Stata version 10 (Stata Corp, College Station, TX, USA).

\section{Results}

\section{Participants}

Eighty five patients with sepsis and 45 control patients were enrolled in the study. Two sepsis patients and four controls were excluded from further analysis because they refused blood collection. Of the remaining 83 sepsis patients, 52 had organ dysfunction due to sepsis at baseline (severe sepsis group) and 31 did not (sepsis without organ failure). The three groups were well matched in terms of risk factors for endothelial dysfunction and other baseline characteristics (Table 1).

\section{Baseline Ang-2 and VEGF}

Plasma Ang-2 concentrations were raised in sepsis in proportion to disease severity (Table 2 and Figure 1a). Median Ang-2 concentrations ( $\mathrm{ng} / \mathrm{ml}$ (interquartile range (IQR)) were two-fold higher in patients with severe sepsis (12.4 (8.5 to 33.4)), than in those with sepsis without organ failure (6.1 (5.0 to 10.4); $P<0.0001$ ), and 4.5-fold higher than in controls (2.7 (2.2 to 3.6), $P<0.0001)$. The difference in Ang-2 between sepsis without organ failure and controls was also significant $(P<0.0001)$. VEGF was also raised in sepsis patients compared with controls $(P=0.0001$, Table 2 and Figure $1 \mathrm{~b})$, but the difference in VEGF between severe sepsis and sepsis without organ failure was not significant.

\section{Ang-2 and disease severity}

Ang-2 correlated with sepsis severity (Table 3), as measured by Acute Physiology and Chronic Health Evaluation (APACHE) II score $(r=0.46, P<0.0001)$, Sequential Organ Failure Assessment (SOFA) score $(r=0.58$, $P<0.0001)$, number of organ failures $(\mathrm{r}=0.48$, $P<0.0001)$ and arterial lactate $(\mathrm{r}=0.41, P=0.003)$, whereas VEGF did not correlate with any of these parameters. As neutrophils release $\mathrm{H}_{2} \mathrm{O}_{2}$, we also examined the relation between neutrophil counts and plasma Ang2 concentrations, and found no significant correlation ( $\mathrm{r}=0.16, P=0.15)$.

\section{Ang-2 and NO-dependent microvascular reactivity}

On univariate analysis, Ang-2 was inversely correlated with RH-PAT index, an estimate of endothelial NO bioavailability $(r=-0.38, P<0.0001)$, and positively correlated with markers of endothelial activation (ICAM-1 $\mathrm{r}=0.58, P \leq 0.0001$, E-selectin $\mathrm{r}=0.53, P<0.0001$ ). VEGF did not correlate with endothelial NO

Table 1 Baseline characteristics of participants

\begin{tabular}{|c|c|c|c|c|}
\hline & Severe sepsis & Sepsis without organ failure & Control & $P$ value across all groups \\
\hline $\mathbf{N}$ & 52 & 31 & 41 & \\
\hline Age (years) ${ }^{a}$ & $52.8(48.6-56.9)$ & $50.8(46.5-55.2)$ & $47.3(43.2-51.6)$ & $N S^{c}$ \\
\hline Male n (\%) & $31(60)$ & $21(68)$ & $28(68)$ & $N S^{d}$ \\
\hline Diabetic n (\%) & $17(33)$ & $7(23)$ & $13(32)$ & $N S^{d}$ \\
\hline Smoker n (\%) & $26(50)$ & $12(39)$ & $16(39)$ & $N S^{d}$ \\
\hline IHD n (\%) & $9(17)$ & $6(19)$ & $5(12)$ & $N S^{d}$ \\
\hline On a statin n (\%) & $13(25)$ & $9(29)$ & $11(27)$ & $N S^{d}$ \\
\hline APACHE $\|^{b}$ & $19(15-25)$ & $8(5-11)$ & & $0.0001^{e}$ \\
\hline SOFA score ${ }^{b}$ & $6(3-9)$ & $1(0-2)$ & & $0.0001^{e}$ \\
\hline
\end{tabular}

a. Mean (95\% confidence interval).

b. Median (Interquartile range).

c. By one-way analysis of variance.

d. By Fisher's exact test across all three groups.

e. By Kruskal-Wallis test.

APACHE II, Acute Physiology and Chronic Health Evaluation II score; IHD, ischemic heart disease; NS, not significant; SOFA, Sequential Organ Failure Assessment score. 
Table 2 Baseline measurements according to disease category

\begin{tabular}{|c|c|c|c|c|}
\hline & Severe sepsis & Sepsis without organ failure & Control & $P$ value across all groups \\
\hline $\mathbf{N}$ & 52 & 31 & 41 & \\
\hline Angiopoietin $2(\mathrm{ng} / \mathrm{ml})^{\mathrm{a}}$ & $12.44(8.47-33.44)$ & $6.11(4.59-10.37)$ & $2.71(2.15-3.61)$ & $0.0001^{d}$ \\
\hline $\operatorname{VEGF}(\mathrm{pg} / \mathrm{ml})^{\mathrm{a}}$ & $98.4(56.4-142.6)$ & $80.8(57.5-147.3)$ & $52.3(31.8-73.5)$ & $0.0007^{d}$ \\
\hline Plasma ICAM-1 (ng/ml) ${ }^{a}$ & $846(523-1483)$ & $501(368-672)$ & $323(265-393)$ & $0.0001^{d}$ \\
\hline Plasma E-selectin $(\mathrm{ng} / \mathrm{ml})^{\mathrm{a}}$ & $200.5(113-478)$ & $87.0(50.8-164.4)$ & $38.4(26.9-58.2)$ & $0.0001^{d}$ \\
\hline RH-PAT index ${ }^{b}$ & $1.57(1.44-1.71)$ & $1.85(1.67-2.03)$ & $2.07(1.93-2.22)$ & $<0.0001^{e}$ \\
\hline Plasma interleukin $6(\mathrm{pg} / \mathrm{ml})^{\mathrm{a}}$ & $385.1(124.2-996.0)$ & $148.3(45.9-315.0)$ & $5.0(2.2-8.1)$ & $0.0001^{d}$ \\
\hline Plasma TNF $\alpha \geq 2.8 \mathrm{pg} / \mathrm{ml}(\mathrm{n}, \%)^{\mathrm{c}}$ & $8(22)$ & $4(14)$ & $5(17)$ & $N S^{f}$ \\
\hline
\end{tabular}

a. Median (Interquartile range).

b. Mean ( $95 \%$ confidence interval).

c. $2.8 \mathrm{pg} / \mathrm{ml}$ is the lower limit of detection for the assay used for TNF $\alpha$.

d. By Kruskal-Wallis test.

e. By oneway analysis of variance.

f. By Fisher's exact test across all three groups.

ICAM-1, intra-cellular adhesion molecule-1; NS, not significant; RH-PAT, reactive hyperemia peripheral arterial tonometry; TNF $\alpha$, tumor necrosis factor $\alpha$; VEGF, vascular endothelial growth factor.

bioavailability, endothelial activation or plasma Ang-2. The relationship between log Ang-2 and RH-PAT index remained significant after controlling for disease severity using SOFA score.

In a longitudinal analysis, plasma Ang-2 concentrations decreased significantly between day 0 (median (IQR) 10.16 (5.32 to 19.39)) and day two to four (8.72 (5.38 to 15.73), $P=0.01$; Table 4). RH-PAT index increased over the same time period, but the change was not statistically significant (Day 0 mean index 1.67 (95\% confidence interval (CI): 1.55 to 1.78$)$, day two to four $=1.85(1.70$ to2.00)). In a mixed-effects linear regression model, increase in RH-PAT index over the first two to four days correlated significantly with fall in Ang-2 $(r=0.45$, $P<0.0001)$; change in RH-PAT index over time did not correlate with VEGF, ICAM-1, E-selectin, SOFA score, or IL-6.

\section{Ang-2 and markers of inflammation}

Plasma TNF $\alpha$ was below the lower limit of detection in the majority of patients in both the sepsis and control groups (Table 2). In those in whom it was detectable $(\geq 2.8 \mathrm{pg} / \mathrm{ml})$, there was no relation between Ang- 2 and TNFa $(\mathrm{r}=0.24, P=0.44)$. Ang- 2 correlated with IL-6 $(\mathrm{r}=0.57, P<0.0001)$, but not with $\mathrm{C}$-reactive protein or white blood cell count.

\section{Multivariate analysis of correlates of angiopoietin-2}

The variables included in the initial multivariate linear regression model, with log Ang-2 as the dependent variable, were: RH-PAT index, serum albumin, APACHE and SOFA scores, plasma concentrations of E-selectin, ICAM-1, IL-6 and IL-10, and peripheral blood platelet and white blood cell counts. The independent variables that remained significant in the final model, along with their $\beta$ coefficients $(95 \% \mathrm{CI})$ were: $\mathrm{RH}-\mathrm{PAT}$ index $(\beta=$ -0.35 (-0.64 to -0.06$)$ ), ICAM-1 (ng/ml, $\beta=3.8 \times 10^{-4}$ $\left(1.4\right.$ to $\left.\left.6.3 \times 10^{-4}\right)\right)$, IL-6 $\left(\mathrm{pg} / \mathrm{ml}, \beta=1.7 \times 10^{-4}(0.05\right.$ to $\left.\left.2.9 \times 10^{-4}\right)\right)$, platelet count $\left(\times 10^{9} / \mathrm{L}, \beta=-2 \times 10^{-3}(-3.2\right.$ to $\left.\left.-0.90 \times 10^{-3}\right)\right)$, and white blood cell count $\left(\times 10^{9} / \mathrm{L}\right.$, $\beta=3.2 \times 10^{-2}\left(1.1\right.$ to $\left.5.2 \times 10^{-2}\right)$.

\section{Outcomes}

The median (IQR) length of stay in the ICU among all sepsis patients was 5.4 (3.0 to 8.4) days, and this was significantly correlated with baseline Ang-2 $(r=0.30$, $P=0.03$ ). Of the 83 patients with sepsis, only 8 had died at 28 -day follow up (10\%). Seven of these were from the severe sepsis group (28-day mortality $13 \%$ ) and one was from the sepsis without organ failure group (mortality $3 \%)$. Baseline levels of Ang-2 were not significantly different $(P=0.32)$ in those with fatal $(11.46(7.09$ to 45.12$))$ and non-fatal outcomes (10.04 (5.26 to 18.96)).

\section{Discussion}

Plasma Ang-2 concentrations are raised in patients with sepsis, in proportion to disease severity and endothelial cell activation, and are inversely associated with estimated endothelial NO bioavailability both at baseline and during recovery. This finding supports the hypothesis that impaired endothelial NO bioavailability in sepsis leads to increased exocytosis of WPBs, release of Ang-2, and thus to further endothelial cell sensitization and activation. This hypothesis is also supported by recent findings in patients with severe malaria, where an increase in endothelial NO bioavailability over time (also measured by RH-PAT) was significantly associated with falling plasma Ang-2 levels [23]. 


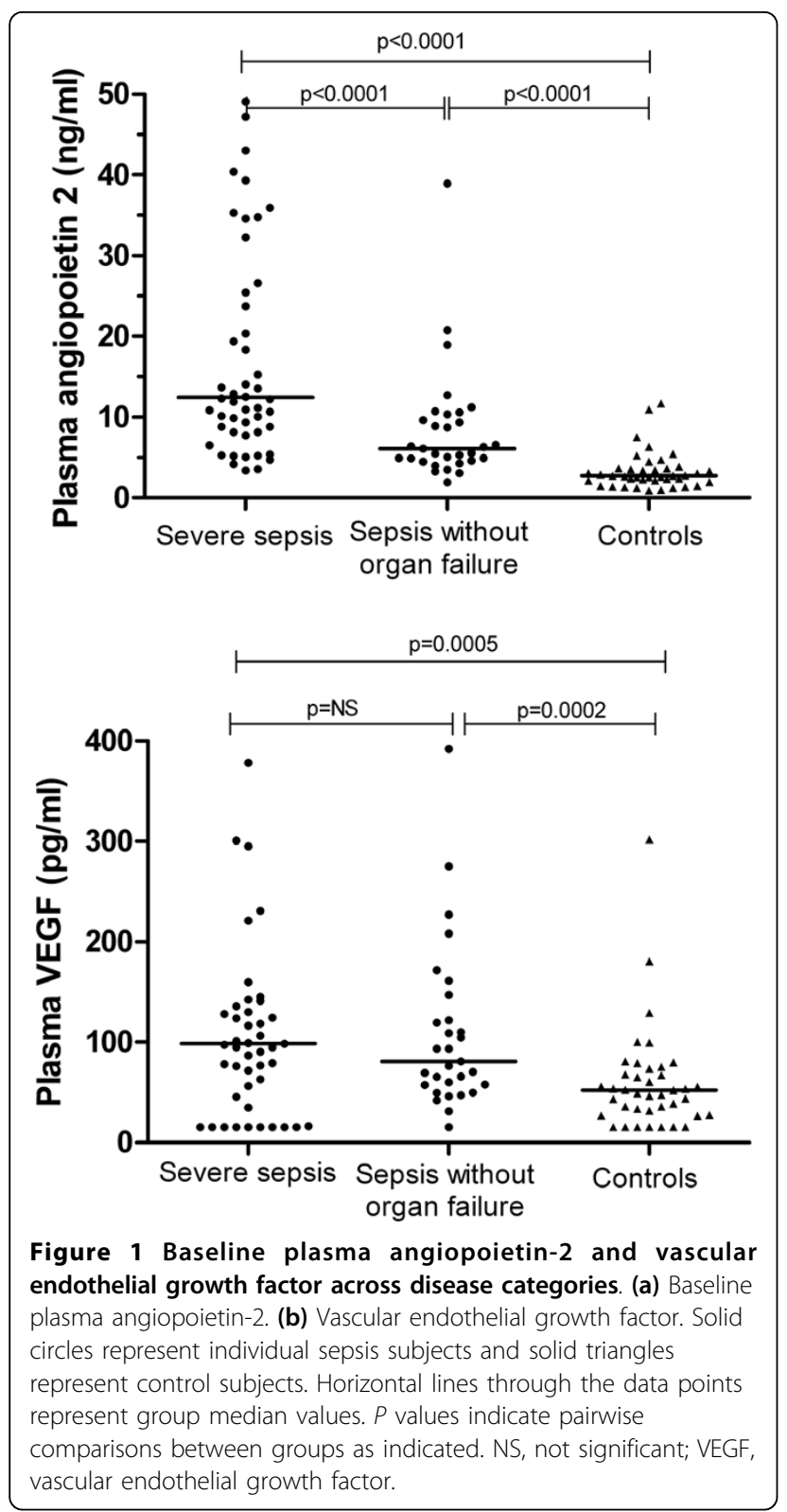

Although we demonstrate for the first time the relation between estimated endothelial NO bioavailability and plasma Ang-2 concentrations in sepsis, there is substantial recent evidence underpinning this hypothesis. In vitro, $\mathrm{NO}$ is the only substance demonstrated to reduce exocytosis of WPBs and release of Ang-2 apart from high concentrations of $\mathrm{H}_{2} \mathrm{O}_{2}[13,14]$. NO reduces WPB exocytosis by facilitating the S-nitrosylation of $\mathrm{N}$-ethyl-malemide sensitive factor (NSF), which results in the inability of the WPB membrane to fuse with the plasma membrane $[2,12,13]$. Furthermore, contrary to previously accepted theories, there is increasing evidence that systemic NO production is normal or decreased rather than increased in sepsis $[18,19]$, and that sepsis is
Table 3 Correlations of baseline plasma angiopoietin- 2 in sepsis patients

\begin{tabular}{llll}
\hline & Spearman's rho & $\mathbf{P}$ & $\mathbf{n}$ \\
\hline Endothelial function and activation & & & \\
RH-PAT index & -0.38 & $<0.0001$ & 74 \\
VEGF & -0.04 & $\mathrm{NS}$ & 80 \\
ICAM-1 & 0.58 & $<0.0001$ & 83 \\
E-Selectin & 0.53 & $<0.0001$ & 83 \\
Markers of inflammation & & & \\
IL-6 & 0.57 & $<0.0001$ & 66 \\
C-reactive protein & 0.16 & $\mathrm{NS}$ & 82 \\
Markers of disease severity & & & \\
SOFA score & 0.58 & $<0.0001$ & 82 \\
APACHE II score & 0.46 & $<0.0001$ & 83 \\
Number of organ failures & 0.48 & $<0.0001$ & 83 \\
Arterial lactate & 0.41 & 0.003 & 51 \\
\hline
\end{tabular}

APACHE II score, Acute Physiology and Chronic Health Evaluation II Score; ICAM-1, intra-cellular adhesion molecule-1; IL-6, interleukin 6; NS, not significant; RH-PAT, reactive hyperemia peripheral arterial tonometry; SOFA, Sequential Organ Failure Assessment score; VEGF, vascular endothelial growth factor.

Table 4 Change in angiopoietin-2 and other variables over time

\begin{tabular}{|c|c|c|c|}
\hline & Day 0 & Day 2-4 & $P$ value $^{a}$ \\
\hline RH-PAT ${ }^{\mathrm{b}}$ & $1.67(1.55-1.78)$ & $1.83(1.67-1.99)$ & NS \\
\hline SOFA score ${ }^{c}$ & $4(2-8)$ & $3(1-7)$ & 0.07 \\
\hline Ang-2 (ng/ml) & $10.16(5.32-19.39)$ & $8.72(5.38-15.73)$ & 0.01 \\
\hline VEGF $(\mathrm{pg} / \mathrm{ml})^{\mathrm{c}}$ & $94.8(57.0-143.8)$ & $73.6(48.6-167.3)$ & NS \\
\hline ICAM-1 $(\mathrm{ng} / \mathrm{ml})^{\mathrm{c}}$ & $655.6(448.0-1084.1)$ & $694.0(450.3-1258.1)$ & NS \\
\hline E-selectin $(\mathrm{ng} / \mathrm{ml})^{\mathrm{c}}$ & $154.5(69.1-396.3)$ & $120.3(63.9-199.2)$ & $<0.0001$ \\
\hline IL-6 $(\mathrm{pg} / \mathrm{ml})^{\mathrm{c}}$ & $224.4(75.0-595.5)$ & $58.1(17.2-255.8)$ & $<0.0001$ \\
\hline
\end{tabular}

a. Mean (95\% confidence interval).

b. Median (Interquartile range).

c. Wilcoxon's paired signrank test.

Ang-2, angiopoietin-2; ICAM-1, intra-cellular adhesion molecule-1; IL-6, interleukin 6; NS, not significant; RH-PAT, reactive hyperemia peripheral arterial tonometry; SOFA, Sequential Organ Failure Assessment score; VEGF, vascular endothelial growth factor.

a state of imbalance between the endothelial and inducible isoforms of NO synthase in the microvasculature, resulting in a relative deficiency of endothelial NO $[24,25]$. The fact that non-specific NO inhibitors increase mortality in patients with sepsis [26] supports this idea, and it is possible that increased Ang-2 release is one of the mechanisms underlying this finding.

Clinical studies investigating the endothelium in sepsis commonly use circulating markers of endothelial cell activation as a surrogate measure of endothelial function. We have previously shown that ICAM-1 and E-selectin, two of the most commonly used markers of endothelial activation in sepsis, do not correlate with endothelial function as measured by RH-PAT [15]. In contrast, Ang-2 correlates with endothelial function as 
measured by RH-PAT, both at baseline and longitudinally. Thus Ang-2 is a more meaningful biomarker of endothelial cell function in sepsis than currently used surrogate measures.

Endothelial cell activation in sepsis increases vascular leak, triggers a pro-coagulant state, up-regulates adhesion molecule expression, and further drives the inflammatory response [27]. Together, these processes cause regional hypoperfusion and acute organ dysfunction. By mediating autocrine activation of local endothelial cells, Ang-2 may exacerbate tissue hypoperfusion and inflammation, providing a plausible mechanism for its independent association with organ failure and mortality in sepsis [7].

In-vitro studies of Ang-2 demonstrate that in the absence of Ang-2, a TNF $\alpha$ concentration of $40 \mathrm{pg} / \mathrm{ml}$ or more is required to independently activate endothelial cells, whereas in the presence of Ang-2 at a concentration of $2000 \mathrm{pg} / \mathrm{ml}$, a TNF $\alpha$ concentration of $5 \mathrm{pg} / \mathrm{ml}$ or more is able to cause endothelial activation [28]. Plasma TNF $\alpha$ levels in sepsis patients in this study were relatively low, with only 1 of 69 sepsis patients having TNF $\alpha$ levels of $40 \mathrm{pg} / \mathrm{ml}$ or more, similar to the low levels reported in other sepsis studies [29,30]. The concentrations of Ang- 2 in this and other human sepsis studies $[4,5,7]$ are higher than those used in in-vitro studies, and may sensitize endothelial cells to lower concentrations of TNF $\alpha$. Furthermore, local microvascular TNF $\alpha$ concentrations may be higher than we and others have found in plasma. Nevertheless, taken together our results support the hypothesis that in sepsis, Ang-2 sensitizes endothelial cells to the effects of cytokines that may otherwise cause only minimal or no endothelial activation [28].

The factors triggering Ang-2 release from WPBs in sepsis are not known. Thrombin [12], VEGF [31] and, in some [31,32], but not other studies $[4,12]$, TNF $\alpha$, cause WPB release in-vitro. However, we found that neither TNFa nor VEGF correlated with Ang-2. Although we found a strong independent association between IL-6 and Ang-2, IL- 6 has not been shown to cause exocytosis of WPBs or secretion of Ang-2 in vitro. IL-6 is an important pro-inflammatory cytokine and correlates with disease severity in sepsis. Bacterial lipopolysaccharide increases Ang-2 levels [33] and drives IL6 expression [30], and such factors may account for this association.

Although Ang-2 correlated with length of stay in this study, it did not correlate with mortality. Despite a median APACHE II score of 19, and a consequent predicted mortality of $34.8 \%$ [34], there were few deaths in our study ( 8 in total, $13 \%$ within the severe sepsis group). This is consistent with the previously reported low mortality from severe sepsis in our ICU [35], and suggests that our study was under-powered to examine the relation between Ang-2 and mortality. However, in studies with higher numbers of deaths, Siner and colleagues and Kumpers and colleagues both found a clear association between plasma Ang-2 levels and risk of mortality $[7,8]$.

Although we did not directly measure endothelial cell NO concentrations (which is not possible in septic patients), RH-PAT index is an indirect measurement of NO bioavailability and is at least $50 \%$ NO-dependent in healthy volunteers [16]. Other methods of measuring $\mathrm{NO}$ in patients with sepsis, such as plasma NO metabolites, are not specific to the endothelium and are confounded by nitrate retention in renal failure [36]. Thus it is not possible to directly confirm the relation between endothelial NO bioavailability and plasma Ang2 using currently available methods in humans with sepsis.

The correlation between Ang-2 and RH-PAT index was statistically significant but was not strong. We cannot exclude an alternative explanation for the inverse association between Ang-2 and endothelial NO bioavailability: that increased Ang-2 release in sepsis leads to decreased NO bioavailability as a consequence of upregulated endothelial cell inflammation and superoxidemediated NO quenching. Nevertheless the clear in vitro evidence for NO as the major inhibitor of WPB exocytosis and Ang-2 release, and the findings in other disease settings such as malaria [23], make it more likely that impaired NO bioavailability is a significant contributor to Ang-2 release in sepsis.

vWF is co-packaged with Ang-2 in WPBs but is also released by activated platelets, and is thus less specific for endothelial cells. Although not measured in our study, plasma vWF activity is known to be increased in patients with sepsis, and to correlate with mortality [37]. Like other markers of endothelial cell activation, vWF has not been compared with measures of endothelial NO bioavailability in sepsis. However, in non-septic patients with risk factors for cardiovascular disease, vWF is raised, correlates with endothelial activation as measured by E-selectin [38], and is inversely proportional to endothelial NO bioavailability as estimated by flow-mediated dilatation of the brachial artery [39]. Furthermore, plasma vWF is raised in proportion to plasma Ang-2 in patients with sepsis and acute lung injury [11]. Because our results suggest that impaired endothelial NO bioavailability exacerbates WPB release, they provide a plausible explanation for the increase in both Ang-2 and vWF in patients with sepsis.

\section{Conclusions}

In conclusion, Ang-2 is raised in sepsis in proportion to disease severity and correlates with endothelial 
activation and inversely with NO-dependent microvascular reactivity, both at baseline and over the first two to four days of treatment. This suggests that decreased endothelial NO bioavailability may contribute to Ang-2 release by reducing negative feedback on WPBs, thus augmenting endothelial cell activation and contributing to organ dysfunction. Adjunctive therapies which improve endothelial NO, decrease WPB release, or antagonise Ang-2 may have roles in reducing organ dysfunction and improving mortality in sepsis.

\section{Key messages}

- Plasma concentrations of Ang-2, an angiogenic peptide, have been shown to be raised in patients with sepsis and to correlate with organ failure and mortality, but the underlying mechanisms are unclear.

- In-vitro, NO inhibits Ang-2 release from endothelial cells. In this study, plasma concentrations of Ang-2 in septic patients were raised in proportion to disease severity, and were inversely proportional to estimated endothelial NO bioavailability.

- Decreased endothelial NO bioavailability in sepsis may be the mechanism for raised Ang-2 concentrations, thus contributing to capillary leak and organ dysfunction.

- Adjunctive therapies that improve endothelial NO or antagonise Ang-2 may have roles in reducing organ dysfunction and improving mortality in sepsis.

\section{Abbreviations}

Ang-2: angiopoietin-2; APACHE: Acute Physiology and Chronic Health Evaluation; CBA: cytokine bead array; Cl: confidence interval; ELISA: enzymelinked immunosorbent assay; $\mathrm{H}_{2} \mathrm{O}_{2}$ : hydrogen peroxide; ICAM-1: intra-cellular adhesion molecule-1; IL: interleukin; IQR: interquartile range; NSF: N-ethylmalemide sensitive factor; NO: nitric oxide; RH-PAT: reactive hyperemia peripheral arterial tonometry; SIRS: systemic inflammatory response syndrome; SOFA: Sequential Organ Failure Assessment; TNFo: tumour necrosis factor $\alpha$; VEGF: vascular endothelial growth factor; vWF: von Willebrand factor; WPB: Weibel Palade bodies.

\footnotetext{
Acknowledgements

We wish to thank the following people for their contribution to this work: Jane Thomas, Mark McMillan, Karl Blenk, Antony Van Assche, Paulene Kittler and Steven Tong for recruitment of patients and data collection; Christabelle Darcy, Catherine Jones and Barbara McHunter for laboratory assays; Joseph McDonnell and Ric Price for statistical advice; The medical and nursing staff of the Royal Darwin Hospital Intensive Care Unit and Hospital in the Home; and of course all the patients who kindly agreed to be a part of this study. Funding sources: The study was funded by the National Health and Medical Research Council of Australia (Program Grants 290208, 496600; Practitioner Fellowship to NMA, Scholarship to JSD).

\section{Author details}

'International Health Division, Menzies School of Health Research and Charles Darwin University, Ellengowan Drive, Casuarina, Darwin, NT 0810, Australia. ${ }^{2}$ Department of Infectious Diseases, Royal Darwin Hospital, Rocklands Drive, Tiwi, Darwin, NT 0810, Australia. ${ }^{3}$ Department of Medicine, University of Sydney and Department of Cardiology, Royal Prince Alfred Hospital, Missenden Road, Camperdown, Sydney, NSW 2006, Australia. ${ }^{4}$ Intensive Care Unit, Royal Darwin Hospital, Rocklands Drive, Tiwi, Darwin, NT, 0810, Australia.
}

\section{Authors' contributions}

Study Design was performed by JSD, NMA, TWY, DPS and DSC. JSD and DPS contributed to patient recruitment. The data was processed by JSD, KP and TW, and was analysed by JSD. Laboratory sample processing was performed by KP and TW. The manuscript was drafted by JSD and NMA. All authors had access to all data and contributed to the final draft of the paper. All authors read and approved the final manuscript.

\section{Competing interests}

DC has received research support (as equipment) from Itamar Medical, the manufacturer of the RH-PAT device, and has received speaker's fees (less than US\$1000 per year) for speaking at Itamar-sponsored educational events. The other authors have no competing interests.

Received: 20 November 2009 Revised: 2 February 2010

Accepted: 18 May 2010 Published: 18 May 2010

\section{References}

1. Aird WC: The role of the endothelium in severe sepsis and multiple organ dysfunction syndrome. Blood 2003, 101:3765-3777.

2. Fiedler $U$, Augustin HG: Angiopoietins: a link between angiogenesis and inflammation. Trends Immunol 2006, 27:552-558.

3. Yuan HT, Khankin EV, Karumanchi SA, Parikh SM: Angiopoietin 2 is a partial agonist/antagonist of Tie2 signaling in the endothelium. Mol Cell Biol 2009, 29:2011-2022.

4. Orfanos SE, Kotanidou A, Glynos C, Athanasiou C, Tsigkos S, Dimopoulou I, Sotiropoulou C, Zakynthinos S, Armaganidis A, Papapetropoulos A, Roussos C: Angiopoietin-2 is increased in severe sepsis: correlation with inflammatory mediators. Crit Care Med 2007, 35:199-206.

5. Giuliano JS Jr, Lahni PM, Harmon K, Wong HR, Doughty LA, Carcillo JA, Zingarelli B, Sukhatme VP, Parikh SM, Wheeler DS: Admission angiopoietin levels in children with septic shock. Shock 2007, 28:650-654.

6. Kranidioti H, Orfanos SE, Vaki I, Kotanidou A, Raftogiannis M, Dimopoulou I, Kotsaki A, Savva A, Papapetropoulos A, Armaganidis A, GiamarellosBourboulis EJ: Angiopoietin-2 is increased in septic shock: evidence for the existence of a circulating factor stimulating its release from human monocytes. Immunol Lett 2009, 125:65-71.

7. Siner JM, Bhandari V, Engle KM, Elias JA, Siegel MD: Elevated serum angiopoietin 2 levels are associated with increased mortality in sepsis. Shock 2009, 31:348-353.

8. Kumpers P, Lukasz A, David S, Horn R, Hafer C, Faulhaber-Walter R, Fliser D, Haller $\mathrm{H}$, Kielstein JT: Excess circulating angiopoietin-2 is a strong predictor of mortality in critically ill medical patients. Crit Care 2008, 12: R147.

9. Kumpers P, Hafer C, David S, Hecker H, Lukasz A, Fliser D, Haller H, Kielstein JT, Faulhaber-Walter R: Angiopoietin-2 in patients requiring renal replacement therapy in the ICU: relation to acute kidney injury, multiple organ dysfunction syndrome and outcome. Intensive Care Med 2010, 36:462-470.

10. Parikh SM, Mammoto T, Schultz A, Yuan HT, Christiani D, Karumanchi SA, Sukhatme VP: Excess circulating angiopoietin-2 may contribute to pulmonary vascular leak in sepsis in humans. PLOS Med 2006, 3:e46.

11. Heijden van der $M$, van Nieuw Amerongen GP, Koolwijk $P$, van Hinsbergh WW, Groeneveld AB: Angiopoietin-2, permeability oedema, occurrence and severity of ALI/ARDS in septic and non-septic critically ill patients. Thorax 2008, 63:903-909.

12. Fiedler U, Scharpfenecker M, Koidl S, Hegen A, Grunow V, Schmidt JM, Kriz W, Thurston G, Augustin HG: The Tie-2 ligand angiopoietin-2 is stored in and rapidly released upon stimulation from endothelial cell WeibelPalade bodies. Blood 2004, 103:4150-4156.

13. Lowenstein CJ, Morrell CN, Yamakuchi M: Regulation of Weibel-Palade body exocytosis. Trends Cardiovasc Med 2005, 15:302-308.

14. Matsushita K, Morrell CN, Cambien B, Yang SX, Yamakuchi M, Bao C, Hara MR, Quick RA, Cao W, O'Rourke B, Lowenstein JM, Pevsner J, Wagner DD, Lowenstein CJ: Nitric oxide regulates exocytosis by S-nitrosylation of N-ethylmaleimide-sensitive factor. Cell 2003, 115:139-150.

15. Davis JS, Yeo TW, Thomas JH, McMillan M, Darcy CJ, McNeil YR, Cheng AC, Celermajer DS, Stephens DP, Anstey NM: Sepsis-associated microvascular dysfunction measured by peripheral arterial tonometry: an observational study. Crit Care 2009, 13:R155. 
16. Nohria A, Gerhard-Herman M, Creager MA, Hurley S, Mitra D, Ganz P: Role of nitric oxide in the regulation of digital pulse volume amplitude in humans. J Appl Physiol 2006, 101:545-548.

17. Landry DW, Oliver JA: The pathogenesis of vasodilatory shock. $N$ Engl J Med 2001, 345:588-595.

18. Kao CC, Bandi V, Guntupalli KK, Wu M, Castillo L, Jahoor F: Arginine, citrulline, and nitric oxide metabolism in sepsis. Clin Sci (Lond) 2009 117:23-30

19. Luiking YC, Poeze M, Ramsay G, Deutz NE: Reduced citrulline production in sepsis is related to diminished de novo arginine and nitric oxide production. Am J Clin Nutr 2009, 89:142-152

20. Bone RC, Balk RA, Cerra FB, Dellinger RP, Fein AM, Knaus WA, Schein RM, Sibbald WJ: Definitions for sepsis and organ failure and guidelines for the use of innovative therapies in sepsis. The ACCP/SCCM Consensus Conference Committee. American College of Chest Physicians/Society of Critical Care Medicine. Chest 1992, 101:1644-1655.

21. Kuvin JT, Mammen A, Mooney P, Alsheikh-Ali AA, Karas RH: Assessment of peripheral vascular endothelial function in the ambulatory setting. Vasc Med 2007, 12:13-16.

22. Yeo TW, Lampah DA, Gitawati R, Tjitra E, Kenangalem E, McNeil YR, Darcy CJ, Granger DL, Weinberg JB, Lopansri BK, Price RN, Duffull SB, Celermajer DS, Anstey NM: Impaired nitric oxide bioavailability and L-arginine reversible endothelial dysfunction in adults with falciparum malaria. J Exp Med 2007, 204:2693-2704.

23. Yeo TW, Lampah DA, Gitawati R, Tjitra E, Kenangalem E, Piera K, Price RN, Duffull SB, Celermajer DS, Anstey NM: Angiopoietin-2 is associated with decreased endothelial nitric oxide and poor clinical outcome in severe falciparum malaria. Proc Natl Acad Sci USA 2008, 105:17097-17102.

24. McGown CC, Brookes ZL: Beneficial effects of statins on the microcirculation during sepsis: the role of nitric oxide. Br J Anaesth 2007, 98:163-175.

25. Trzeciak S, Cinel I, Phillip Dellinger R, Shapiro NI, Arnold RC, Parrillo JE, Hollenberg SM: Resuscitating the microcirculation in sepsis: the central role of nitric oxide, emerging concepts for novel therapies, and challenges for clinical trials. Acad Emerg Med 2008, 15:399-413.

26. Lopez A, Lorente JA, Steingrub J, Bakker J, McLuckie A, Willatts S, Brockway M, Anzueto A, Holzapfel L, Breen D, Silverman MS, Takala J, Donaldson J, Arneson C, Grove G, Grossman S, Grover R: Multiple-center, randomized, placebo-controlled, double-blind study of the nitric oxide synthase inhibitor 546C88: effect on survival in patients with septic shock. Crit Care Med 2004, 32:21-30.

27. Pober JS, Sessa WC: Evolving functions of endothelial cells in inflammation. Nat Rev Immunol 2007, 7:803-815.

28. Fiedler U, Reiss Y, Scharpfenecker M, Grunow V, Koidl S, Thurston G, Gale NW, Witzenrath M, Rosseau S, Suttorp N, Sobke A, Herrmann M, Preissner KT, Vajkoczy P, Augustin HG: Angiopoietin-2 sensitizes endothelial cells to TNF-alpha and has a crucial role in the induction of inflammation. Nat Med 2006, 12:235-239.

29. Kellum JA, Kong L, Fink MP, Weissfeld LA, Yealy DM, Pinsky MR, Fine J, Krichevsky A, Delude RL, Angus DC: Understanding the inflammatory cytokine response in pneumonia and sepsis: results of the Genetic and Inflammatory Markers of Sepsis (GenIMS) Study. Arch Intern Med 2007, 167:1655-1663.

30. Bozza FA, Salluh Jl, Japiassu AM, Soares M, Assis EF, Gomes RN, Bozza MT, Castro-Faria-Neto HC, Bozza PT: Cytokine profiles as markers of disease severity in sepsis: a multiplex analysis. Crit Care 2007, 11:R49.

31. Matsushita K, Yamakuchi M, Morrell CN, Ozaki M, O'Rourke B, Irani K, Lowenstein $C$ J: Vascular endothelial growth factor regulation of WeibelPalade-body exocytosis. Blood 2005, 105:207-214.

32. Kim I, Kim JH, Ryu YS, Liu M, Koh GY: Tumor necrosis factor-alpha upregulates angiopoietin-2 in human umbilical vein endothelial cells. Biochem Biophys Res Commun 2000, 269:361-365.

33. Kumpers $P$, van Meurs M, David S, Molema G, Bijzet J, Lukasz A, Biertz F, Haller H, Zijlstra JG: Time course of angiopoietin-2 release during experimental human endotoxemia and sepsis. Crit Care 2009, 13:R64.

34. Knaus WA, Draper EA, Wagner DP, Zimmerman JE: APACHE II: a severity of disease classification system. Crit Care Med 1985, 13:818-829.

35. Stephens DP, Thomas JH, Higgins A, Bailey M, Anstey NM, Currie BJ, Cheng AC: Randomized, double-blind, placebo-controlled trial of granulocyte colony-stimulating factor in patients with septic shock. Crit Care Med 2008, 36:448-454.
36. Granger DL, Anstey NM, Miller WC, Weinberg JB: Measuring nitric oxide production in human clinical studies. Methods Enzymol 1999, 301:49-61.

37. Ware LB, Eisner MD, Thompson BT, Parsons PE, Matthay MA: Significance of von Willebrand factor in septic and nonseptic patients with acute lung injury. Am J Respir Crit Care Med 2004, 170:766-772.

38. Blann AD: Plasma von Willebrand factor, thrombosis, and the endothelium: the first 30 years. Thromb Haemost 2006, 95:49-55.

39. Felmeden DC, Blann AD, Spencer CG, Beevers DG, Lip GY: A comparison of flow-mediated dilatation and von Willebrand factor as markers of endothelial cell function in health and in hypertension: relationship to cardiovascular risk and effects of treatment: a substudy of the AngloScandinavian Cardiac Outcomes Trial. Blood Coagul Fibrinolysis 2003, 14:425-431.

doi:10.1186/cc9020

Cite this article as: Davis et al:: Angiopoietin-2 is increased in sepsis and inversely associated with nitric oxide-dependent microvascular reactivity. Critical Care 2010 14:R89.

\section{Submit your next manuscript to BioMed Central and take full advantage of:}

- Convenient online submission

- Thorough peer review

- No space constraints or color figure charges

- Immediate publication on acceptance

- Inclusion in PubMed, CAS, Scopus and Google Scholar

- Research which is freely available for redistribution

Submit your manuscript at www.biomedcentral.com/submit
Biomed Central 